\title{
LA EXPERIENCIA MEXICANA DE CHARLES WRIGHT MILLS
}

\author{
Elisa Servín \\ Instituto Nacional de Antropología e Historia ${ }^{1}$
}

Es por eso que es en lo político donde deben centrarse la solidaridad y el esfuerzo intelectuales. Si el pensador no se relaciona con el valor de la verdad en la lucha política, no puede hacer frente con responsabilidad al conjunto de la experiencia vital. ${ }^{2}$

Cigaciones Sociales de la Universidad Nacional Autónoma
123 de febrero de 1960 dio inicio en el Instituto de Inves-
de México el seminario "Teoría de la estructura social: marxis-
mo y liberalismo", impartido por el sociólogo estadounidense
C. Wright Mills." Profesor de la Universidad de Columbia en

Fecha de recepción: 28 de enero de 2019

Fecha de aceptación: 19 de junio de 2019

\footnotetext{
${ }^{1}$ Agradezco los comentarios de Eric Zolov y Rafael Rojas a versiones preliminares de este texto.

2 "The powerless people", en The Politics of Truth, p. 19. La versión original de esta cita está en inglés, como todas las que corresponden a Mills y algunas de Arnaldo Orfila Reynal y Carlos Fuentes que fueron escritas originalmente en ese idioma. Por criterios editoriales todas fueron traducidas al español. La traducción es mía.

${ }^{3}$ Excelsior (24 feb. 1960).
} 
Nueva York y autor entre otros libros de The Power Elite y The Sociological Imagination, Mills era en ese momento uno de los sociólogos más reconocidos no sólo en Estados Unidos sino en el ámbito internacional. Sus libros eran ampliamente leídos y discutidos en el campo de las ciencias sociales mientras que su interés por participar en la discusión pública lo hacía frecuente colaborador de revistas y otras publicaciones. Invitado por Lucio Mendieta y Núñez, director del Instituto, y por Pablo González Casanova, en ese momento director de la Escuela Nacional de Ciencias Políticas y Sociales, Mills se encontró en el seminario con un grupo de intelectuales, algunos de ellos profesores de la misma escuela, quienes desde hacía unos meses editaban el espectador con la intención de contribuir a la discusión sobre la renovación de la izquierda y su relación con la agonizante revolución mexicana. Carlos Fuentes, Enrique González Pedrero, Víctor Flores Olea y Jaime García Terrés compartieron y discutieron los planteamientos de Mills en torno a la necesidad de renovar el marxismo y reconstruir a la izquierda en una coyuntura determinada por los realineamientos ideológicos de la Guerra Fría. El grupo compartía con Mills la premisa en torno al papel fundamental que los intelectuales debían tener en esta discusión al comprometerse críticamente con los problemas sociales de su tiempo.

El encuentro de Mills con los intelectuales mexicanos ocurrió en el contexto de gran entusiasmo que la revolución cubana había despertado en América Latina como una fuerza renovadora de la izquierda. Tal y como el propio Mills reconocería más tarde, hasta ese momento su interés por el proceso revolucionario cubano había sido casi inexistente. ${ }^{4} \mathrm{~A}$ su regreso a Nueva York, sin embargo, el sociólogo se propuso acercarse de lleno a la Revolución que era en ese momento uno de los ejes del debate entre la izquierda internacional. Meses después publicaría

${ }^{4}$ Mills, Escucha, yanqui, p. 11. 
su famoso Listen, Yankee, el libro con el que quiso explicar la revolución en Cuba a la opinión pública de su país.

La historiografía se ha referido a este encuentro como parte de los intercambios que produjo la creciente "internacionalización" de Mills y acertadamente ha señalado su relevancia en términos de acercarlo a América Latina y a la revolución cubana en particular. ${ }^{5}$ Considero sin embargo que no se ha analizado a profundidad qué fue lo que encontró Mills en México y sobre todo por qué ese encuentro fue determinante para que decidiera viajar a Cuba. En este texto exploro dos argumentos: por una parte las discusiones con Fuentes, González Pedrero, González Casanova, Flores Olea y García Terrés le confirmaron la importancia que tenía en ese momento una nueva generación de pensadores interesados en la construcción de una "nueva izquierda" a la que Mills habría de dirigirse pocos meses después en su "A Letter to the New Left". En ese texto el sociólogo desarrollaba su convicción a propósito del lugar social y político que correspondía al pensador, al intelectual, al que incluso habría de atribuirle una condición "revolucionaria" como posible vanguardia en la movilización social. ${ }^{6}$ En ese sentido la cubana parecía ser una revolución encabezada por un grupo de jóvenes intelectuales y universitarios, la nueva vanguardia que desde la perspectiva de Mills habría de transformar a la izquierda. Por otra parte los intercambios con sus amigos mexicanos despertaron su interés por Cuba como una posible opción de desarrollo independiente, una tercera vía para los países subdesarrollados, en el lenguaje de la época, que no se sujetara al modelo bipolar encabezado por Estados Unidos y la Unión Soviética. Apenas unos meses antes Mills había participado en un seminario en Brasil en el que

5 Véase por ejemplo Geary, Radical Ambition y Montecinos, "C. Wright Mills and Latin America". Véase también Rojas, Fighting over Fidel, cap. 4 y Treviño, C. Wright Mills and the Cuban Revolution.

${ }^{6}$ C. Wright Mills, “A Letter to the New Left”, en New Left Review, 5 (sep.oct. 1960). 
se encontraba también González Casanova y en el que sugería la posibilidad de que los países latinoamericanos encontraran otras vías de desarrollo, más allá de los modelos del capitalismo estadounidense y el socialismo soviético. ${ }^{7}$

Como lo escribiera en algún momento el propio Fuentes, “[...] en 1960, cuando visitó la Escuela de Ciencias Políticas de la Universidad de México, Mills estaba aún lejos -y sin embargo, tan cerca-del encuentro con Cuba que habría de cambiar su vida [...]" ${ }^{8}$ Encontrarse en México con esa revolución lo llevó a publicar un libro que sería a su vez lectura obligada de esa nueva izquierda que era para él un referente desde su primera visita a Europa en 1956. En los meses siguientes a su visita a México Mills compartió con Carlos Fuentes el interés por articular a una nueva izquierda continental americana que pudiera impulsar una redefinición en la relación entre Estados Unidos y los países de América Latina en la coyuntura de la Guerra Fría. El artículo explora entonces el vínculo de Mills con este grupo por lo que ello implicó en un momento en el que la izquierda intelectual se redefinía y revitalizaba, a la vez que construía nuevas redes transnacionales a la luz de los movimientos de liberación nacional que sacudían distintos países de Asia y África, y por supuesto de la revolución cubana.

\section{WRIGHT MILLS Y EL INTELECTUAL PÚBLICO}

Charles Wright Mills nació en Waco, Texas, en 1916 en el seno de una familia de clase media, hijo de un agente de seguros y una madre católica practicante de origen irlandés que quiso darle una educación religiosa. Sus primeros años de vida los pasó en distintas localidades de Texas, siempre en mudanza por el

\footnotetext{
7 A propósito de este encuentro véase Montecinos, "C. Wright Mills and Latin America", pp. 129 y ss.

${ }^{8}$ Fuentes, La nueva novela hispanoamericana, p. 93.
} 
trabajo de su padre. Siendo ya un adolescente y establecido con su familia finalmente en Dallas, Mills insistió en estudiar la preparatoria en una escuela pública. A un paso de graduarse el joven Wright Mills expresaría, en una carta enviada al Dallas Morning News, su preferencia por la ciencia "que busca la verdad" sobre la religión dogmática "que empieza con 'la verdad”” a propósito de los cuestionamientos al pensamiento científico publicados por un pastor fundamentalista. ${ }^{9}$ La primera expresión pública de su incipiente conciencia crítica le valió la incomodidad de sus padres y la presión familiar para estudiar ingeniería en lo que en ese momento era un colegio militarizado, el Texas Agricultural and Mechanical College (A\&M). Ahí el joven Mills haría de nuevo evidente su capacidad crítica y su postura antiautoritaria en una carta dirigida al periódico estudiantil en la que expresaba su inconformidad con el trato "feudal" que sometía a los estudiantes de primer año a los abusos y maltratos de los del último grado. ${ }^{10} \mathrm{La}$ experiencia en A\&M duró sólo un año y en 1935 Mills ingresó a la Universidad de Texas en Austin, donde realizó estudios de grado y de posgrado en filosofía y sociología. En Austin, Mills se alimentó de las ideas del pragmatismo estadounidense representado por John Dewey y del pensamiento económico de Thorstein Veblen. Algún día el propio Mills diría: "Se pensó que A\&M me haría un hombre. En vez de eso, me convertí en un intelectual”. ${ }^{11}$

En el verano de 1939, mientras los prolegómenos de la segunda guerra mundial incendiaban Europa, Mills ingresó al programa de doctorado en sociología de la Universidad de Wisconsin en Madison, de donde se graduó en 1942. Ahí conoció a Hans Gerth, un profesor alemán exiliado quien lo acercó a la escuela sociológica alemana de Karl Mannheim y Max Weber.

\footnotetext{
9 Geary, Radical Ambition, p. 16.

10 K. Mills y P. Mills (eds.), C. Wright Mills, pp. 30 y ss.

11 The Politics of Truth, p. 4.
} 
Gracias a Gerth, con quien mantuvo una relación de amistad y colaboración no exenta de rivalidad intelectual que duraría toda su vida, Mills no sólo profundizó en la sociología del conocimiento de Mannheim y el pensamiento de Weber sino también en el marxismo, cuya perspectiva teórica contribuiría a alimentar el análisis millsiano de la estructura social con el poder como eje determinante.

Como argumenta Daniel Geary, la temprana conciencia crítica de Mills, intuitivamente empeñada en "ir a la raíz de las cosas", se fortaleció con la formación teórica en las corrientes del pragmatismo y la sociología del conocimiento, lo que le permitió a su vez desarrollar su creciente interés por las relaciones entre el poder y el mundo de las ideas. Ello habría de redundar en su creciente radicalización y en la noción del científico social y el intelectual como un sujeto crítico con un compromiso ético que debería ir a la raíz de la ideología del poder, de las ideas utilizadas por el poder para sostenerse y legitimarse. ${ }^{12}$

En 1941, un año antes de graduarse, Mills aceptó un puesto como profesor en la Universidad de Maryland. A fines de ese mismo año Estados Unidos entró a la segunda guerra mundial. En más de un sentido la estancia en Maryland estaría marcada por la guerra. En primer lugar, por sus esfuerzos para evitar el reclutamiento por distintas vías académicas, que resultaron infructuosos cuando a fines de 1944 recibió una carta para presentarse al servicio militar. El examen médico, sin embargo, lo liberó. A los 28 años ya padecía de hipertensión. ${ }^{13}$

En otro sentido, más importante, el conflicto bélico fue determinante en su creciente radicalización política que correría paralela a una postura antimilitarista, expresada por lo menos desde $1940 .{ }^{14}$ La guerra fortalecería su convicción en torno al

12 Geary, Radical Ambition, pp. 43-44.

13 K. Mills y P. Mills (eds.), C. Wright Mills, p. 68.

${ }^{14}$ En una carta escrita a sus padres en el otoño de 1940 Mills les comentaba que votaría en la elección presidencial de ese año por Norman Thomas, el 
papel del intelectual como un observador crítico de su tiempo que debía participar en la discusión pública. A lo largo de estos años Mills fue una presencia constante en las páginas de New Leader, Partisan Review, New Republic y Politics, las publicaciones más relevantes de la izquierda intelectual neoyorquina, a las que había llegado en un principio por su interés en ampliar sus horizontes intelectuales y trascender los límites de las publicaciones académicas. A principios de diciembre de 1943 Mills le escribió a Gerth a propósito de un texto que recién había escrito en un exabrupto generado por el enojo y el desgaste que le provocaba la guerra y al que pensaba llamar The Politics of Truth..$^{15}$ El joven profesor había descubierto a un "hombre político":

No se había percatado de que la fuente de indignación que se había convertido en su sentimiento político fundamental encubría tan fuertes impulsos políticos. Se identificó con la imagen de ese nuevo hombre político. Lo conducía, como tantas otras cosas, a A\&M en Texas y a la primera cosa que publicó: una carta de protesta contra la disciplina militar. ${ }^{16}$

El texto se publicó en politics en marzo de 1944 con el título "The Powerless People. The Role of the Intellectual in Society", y habría de ser la carta de presentación política de Mills en un momento en el que la izquierda intelectual debatía sobre los

candidato del Partido Socialista, a quien consideraba el único que en verdad se oponía a la guerra, y les pedía que ellos lo hicieran también. K. Mills y P. Mills (eds.), C. Wright Mills, p. 43.

${ }_{15}$ Parte del desgaste tenía que ver con una intensa carga docente pues debía impartir clases de historia a grupos de 150 militares tres veces a la semana, lo que le impedía trabajar en cualquier otra cosa. K. Mills y P. Mills (eds.), C. Wright Mills, p. 54. Meses antes había participado con su amigo, el historiador Richard Hofstadter, en acciones para presionar a la administración de la Universidad con el fin de que diera a conocer sus contratos con el ejército. Brown, Richard Hofstadter, p. 41.

${ }^{16}$ K. Mills y P. Mills (eds.), C. Wright Mills, p. 57. 
efectos de la guerra en el nuevo orden social que surgiría en los años por venir. Para Mills el intelectual estaba derrotado, sus medios de comunicación habían sido expropiados y se encontraba impotente y con miedo a perder su libertad y sus condiciones de trabajo. La vida intelectual se enfrentaba al hecho de que "los centros de la iniciativa política son cada vez más inaccesibles" y pocos hombres decidían el destino de los demás:

Nunca antes tan pocos hombres han tomado decisiones tan fatídicas para tanta gente que a su vez está tan indefensa. Las dictaduras son sólo una de las expresiones de este hecho. Los ejércitos masivos por todo el mundo son su expresión más viva [...] el poder es un monstruo impersonal.

Tomar conciencia del lugar social del intelectual era, sin embargo, una acción política. Que el hombre de ideas explicara su realidad, comunicara su conocimiento, lo era también. No obstante, su conclusión no era optimista: "Le gustaría defender una política de la verdad en una sociedad democráticamente responsable. Sólo que esa lucha que ha hecho en defensa de la libertad para su trabajo ha sido derrotada". ${ }^{17}$

El pesimismo político no frenó su desarrollo académico. En 1945 Mills recibió una oferta de los reconocidos sociólogos Robert K. Merton y Paul Lazarsfeld para ingresar al Departamento de Investigación Social Aplicada de la Universidad de Columbia en Nueva York. Un año después se afiliaría al Departamento de Sociología de la misma Universidad, en la que obtuvo la definitividad en 1956. ${ }^{18}$ Fue en Columbia donde C. Wright Mills escribió los tres libros que lo hicieron uno de los sociólogos más conocidos y debatidos en Estados Unidos: The New Men of Power: America's Labor Leaders (1948), White Collar: The

17 The Politics of Truth, pp. 13-23.

18 K. Mills y P. Mills (eds.), C. Wright Mills, p. 201. 
American Middle Classes (1951) y The Power Elite (1956). Estos conformaron una trilogía analítica de la estructura social y las relaciones de poder en un tiempo al que con ironía llamó de "la celebración americana". La integración de los liderazgos obreros a la lógica de la expansión capitalista de posguerra, el desarrollo de una nueva clase media conformista y apática, manipulada por los medios de comunicación masiva, así como la fusión de las élites económica, política y militar en la cúspide del poder eran los ejes de la nueva sociedad que se consolidaba en el contexto de la Guerra Fría. Lejos del triunfalismo en torno a la nueva hegemonía estadounidense Mills profundizó la crítica al creciente poder que los militares habían adquirido en la vida política como producto de la guerra. El fortalecimiento de la cúpula militar y su alianza con las principales corporaciones económicas y con la clase política tendría efectos nocivos para la democracia estadounidense.

En un contexto de creciente aislamiento académico e intelectual por su radicalismo crítico, en enero de 1956 C. Wright Mills viajó por primera vez a Europa para tomar un curso sobre motocicletas BMW, una de sus aficiones favoritas, en Munich, Alemania. Apenas un mes después, durante el XX Congreso del Partido Comunista de la URSS, Nikita Khrushchev haría una feroz denuncia de los horrores del estalinismo generando una intensa discusión en las filas de la izquierda internacional. Pocos meses después Mills regresó a Europa para una estancia en la Universidad de Copenhague donde impartió un curso sobre psicología social. En noviembre las tropas soviéticas invadían Hungría para detener una revuelta democratizadora. Cuando en marzo de 1957 Mills llegó a Londres para dar tres conferencias en la London School of Economics, se encontró con un grupo de intelectuales enfrascados en una intensa discusión respecto a la necesidad y los caminos para renovar al marxismo y a la izquierda. La renovación del marxismo debía darse a partir de una reivindicación del pensamiento crítico con 
compromiso político, pero sin entrar a las disputas partidarias. La nueva izquierda debía alejarse tanto del estalinismo como de la socialdemocracia en aras de construir una tercera vía, la del socialismo humanista. ${ }^{19} \mathrm{El}$ encuentro de Mills con la llamada nueva izquierda inglesa lo llenó de entusiasmo y le confirmó que el intelectual podía encontrarse a la vanguardia no sólo de la discusión sino también de la acción política.

A partir de su estancia en Londres Mills no sólo se involucró en las discusiones de la nueva izquierda sino también en uno de sus ejes de acción política: la lucha contra las armas nucleares. En un contexto internacional de creciente temor a una conflagración entre adversarios con la misma capacidad destructiva que terminarían por aniquilar a la humanidad, a mediados de 1958 Mills publicó The Causes of World War Three, su primer libro "de bolsillo" dirigido a un público masivo, en el que desarrollaba su postura antibélica y su crítica a las élites de Estados Unidos y la Unión Soviética que, enfrascadas en una carrera armamentista sin fin, parecían llevar a la humanidad hacia el holocausto nuclear. El intelectual, el pensador, el científico y el ministro de cultos tenían la obligación moral de luchar por la paz y sobre todo el compromiso ético de hablar con "la verdad" frente al poder. Mills hacía un llamado a los intelectuales occidentales para que salieran de la autocomplacencia y ejercieran su capacidad crítica frente a los poderes que llevaban al mundo a la hecatombe, al tiempo que señalaba que eran los intelectuales de Europa del este los que con su disidencia política e intelectual habían iniciado el cuestionamiento real de la Guerra Fría en un contexto de autoritarismo y represión. ${ }^{20}$

Un año después, en 1959, C. Wright Mills publicó el libro que lo llevaría a ser considerado el sociólogo más leído de su tiempo y que empezó a escribir durante su estancia en Europa:

19 Out of Apathy, p. 3.

20 Mills, The Causes of World War Three, pp. 149-150. 
The Sociological Imagination, que era una reflexión crítica y renovadora sobre el ejercicio de la sociología y las ciencias sociales que contenía un llamado a recuperar el "oficio" del creador intelectual. En octubre de ese mismo año Mills viajó por primera y única vez a América del Sur para asistir al Seminario Internacional sobre Resistencias al Desarrollo Social organizado por el Centro Latinoamericano de Investigación en Ciencias Sociales que se llevó a cabo en Río de Janeiro, Brasil. Sería éste su primer encuentro con un grupo de sociólogos latinoamericanos entre los que se encontraban L. A. Costa Pinto, director del Centro, Gino Germani, Fernando Henrique Cardoso y el joven director de la Escuela Nacional de Ciencias Políticas de la unam, Pablo González Casanova. ${ }^{21}$

\section{MILLS Y LA “NUEVA IZQUIERDA” MEXICANA}

En 1957 el Fondo de Cultura Económica publicó La élite del poder, el libro que dio a conocer a C. Wright Mills al público hispanohablante y lo acercó al mundo académico e intelectual de América Latina. El editor argentino Arnaldo Orfila Reynal, director del Fondo, daba así inicio a la que habría de convertirse tres años después en una cordial relación entre el sociólogo estadounidense y un pequeño grupo de intelectuales en México en la coyuntura de la naciente revolución cubana.

A mediados de julio de 1959 Orfila le escribió a Mills para comentarle que estaba en tratos con la Oxford University Press para traducir The Sociological Imagination, recién publicado, pero sobre todo para invitarlo a participar en la conmemoración de los 25 años de la editorial. La intención era que hubiera un autor latinoamericano, un europeo y un estadounidense como representativos del grupo de autores de la casa, y de todos los estadounidenses publicados por la editorial, le decía Orfila,

${ }^{21}$ Montecinos, “C. Wright Mills and Latin America”, pp. 129 y ss. 
querían que fuera Mills quien acudiera como invitado especial. La ceremonia conmemorativa estaría encabezada por el presidente de la República y esperaban que Mills pudiera decir algunas palabras tal como lo harían otros "dos o tres intelectuales”. Orfila lo invitaba también a participar en un simposio que se llevaría a cabo en el Fondo con el tema "El papel del intelectual en el mundo de hoy". Concluía su carta señalando que Mills tenía muchos amigos en México que admiraban su trabajo aunque no lo conocieran personalmente. ${ }^{22}$

Entre estos amigos destacaban Carlos Fuentes, Enrique González Pedrero, Víctor Flores Olea y Jaime García Terrés, quienes junto con Francisco López Cámara y Luis Villoro habían iniciado en mayo la publicación de una nueva revista mensual, el espectador -así, con minúsculas-, que surgía, de acuerdo a la presentación del primer número, “en momentos de crisis” y cuando la opinión pública parecía estar enclaustrada entre "la abstención y la tácita censura”. Los editores de la revista se proponían expresamente "luchar, desde ahora, por eso que exigen todos: el ejercicio efectivo de la democracia en México”, y lo harían desde una clara postura de izquierda: "Pero los editores de EL ESPECTADOR no creen que "izquierda" y "sectarismo" sean sinónimos. Una izquierda válida, por definición, es una izquierda abierta, porque reúne a los sectores mayoritarios de una nación. La izquierda, en México, debe ser idéntica a democracia política y a justicia económica". ${ }^{23}$ Con esas palabras el grupo expresaba su interés por contribuir a la renovación de una izquierda que, enfrascada en disputas intrapartidarias, veía pasar desde su aislamiento a las grandes movilizaciones obreras y campesinas que habían sacudido al país en los meses anteriores.

22 AHFCE, Carta de Orfila a Mills, 17 de julio de 1959, exp. 73/2112, Charles W. Mills (CWM). En octubre de ese año la Revista de la Universidad dio a conocer el texto de Mills "La última oportunidad de los intelectuales", publicado originalmente en Esquire, 52 (oct. 1959).

23 el espectador, 1 (mayo 1959), pp. 2 y 3. 
El llamado de "los espectadores" ponía en el eje de la discusión a una nueva generación de intelectuales críticos que buscaban darle un sentido político al esfuerzo de renovación que hasta ese momento habían realizado sobre todo en el campo cultural, como era el caso de la Revista Mexicana de Literatura. ${ }^{24}$

Apenas unos meses antes el grupo había compartido las páginas de Cuadernos Americanos, la revista dirigida por Jesús Silva Herzog, exponiendo sus ideas en torno a tres preguntas fundamentales: “¿Cuál es la situación actual de la Revolución Mexicana? ¿Cuál será la tarea principal de los grupos revolucionarios en el futuro inmediato? ¿Cuál debe ser-dentro de esa situación y de acuerdo con esa tarea- el papel de los intelectuales?”. ${ }^{25}$ Con algunas diferencias de matiz coincidían en el agotamiento de la Revolución que, al institucionalizarse y alejarse de las causas populares, se había convertido tan solo en un discurso demagógico. Quedaba como tarea esencial recuperar y luchar por los intereses populares, campesinos y obreros, y construir una democracia verdadera. Los intelectuales debían ejercer su función crítica, generar conciencia social y, sobre todo, actuar por las causas que la Revolución había abandonado. ${ }^{26}$

Ya desde abril de 1958, en una entrevista concedida a Elena Poniatowska para el suplemento "México en la Cultura" a raíz de la publicación de La región más transparente, Fuentes había expresado una crítica al mundo literario mexicano "que ha infectado a nuestra literatura de una enfermedad más perniciosa: el miedo a llamar las cosas por su nombre. La literatura mexicana tiene el campeonato mundial del eufemismo. Esta actitud

24 Pozas, "La Revista Mexicana de Literatura, pp. 55-78; Deborah CoHn, “The Mexican Intelligentsia, 1950-1968”. Véase también CAREAGA, Los intelectuales y la política en México.

25 Para un análisis sobre el objetivo y los argumentos que se plantearon en ese debate véase HurTado, "Un antecedente de El Espectador”, pp. 15-25. Sobre Cuadernos Americanos, véase WeInberg, “Cuadernos Americanos”.

26 Cuadernos Americanos (ene.-feb. 1959), 1, pp. 44-75. 
ha conducido, a la postre, al mutismo y a la irresponsabilidad crítica que hoy nos afecta". El país se encontraba inmerso en una coyuntura de sucesión presidencial y faltaba la crítica intelectual a la problemática política y social, y sobre todo al evidente agotamiento de la revolución de $1910 .{ }^{27}$ Como una muestra de la actitud comprometida que el escritor esperaba de sus colegas, Fuentes firmaría junto con Fernando Benítez, Jaime García Terrés y Octavio Paz, entre varios otros, un desplegado en apoyo de las movilizaciones estudiantiles y obreras que sacudieron a la Ciudad de México pocos meses después. ${ }^{28}$

De acuerdo a Flores Olea, sería la represión contra Demetrio Vallejo y el movimiento ferrocarrilero al inicio del gobierno de Adolfo López Mateos, así como el reciente triunfo de los revolucionarios en Cuba, lo que llevó al grupo a crear el espectador. Con el apoyo de Silva Herzog, quien les proporcionó 25000 pesos de financiamiento para publicar dos números, empezaron a reunirse en el café El Carmel de la Zona Rosa: "Ese café era de don Jacobo Glantz, el padre de Margo. Nos sentábamos a planear los números, diseñar y corregir pruebas". Con una dirección rotativa y un tiraje inicial de 2000 ejemplares la revista llegó a vender por medio de suscripciones hasta 10000 ejemplares. ${ }^{29}$

El grupo se proponía abrir nuevos canales de expresión para una izquierda intelectual en ascenso en una coyuntura muy particular de la vida pública mexicana. En ese sentido, tal y como lo señala Jaime Pensado, el espectador habría de ser la primera "voz de la Nueva Izquierda en México". ${ }^{30}$ Parte esencial de su propuesta era salir de "la cortina de nopal" a la que se había referido el pintor José Luis Cuevas en 1956 y compartir las discusiones

27 México en la Cultura (4 abr. 1958). Tomado de Relatos e historias en México (jul. 2012).

${ }_{28}$ Desplegado “Al pueblo y al gobierno", Excelsior (30 ago. 1958), p. 16A. Pensado, Rebel Mexico, p. 152.

29 "El Espectador, tribuna juvenil”, El Universal (21 nov. 2008).

30 Pensado, Rebel Mexico, p. 139. 
que se llevaban a cabo en otras latitudes. ${ }^{31}$ Los editores de la revista, todos con una sólida formación académica que incluía posgrados en universidades europeas, estaban al tanto de los debates que se habían generado en la izquierda europea a raíz de la invasión de Hungría por las tropas soviéticas en 1956 y buscaban hacer de la revista un foro intelectual cosmopolita con la mirada puesta no solo en México sino en el intenso acontecer internacional. ${ }^{32}$ Con secciones dedicadas a América Latina, España y otra llamada Internacional, además de traducciones de artículos de revistas europeas y estadounidenses, el espectador se proponía ofrecer a los lectores mexicanos una ventana al mundo en una coyuntura determinada por intensos cambios y novedosos debates. En el segundo número, correspondiente a junio de 1959, por ejemplo, se publicó traducida al español una petición de intelectuales al $86^{\circ}$ Congreso de los Estados Unidos para que se abandonaran los experimentos con armas nucleares y se dejara de utilizar la ayuda económica como recurso de la Guerra Fría. Firmaba entre otros C. Wright Mills.

El profesor Mills no pudo asistir a la conmemoración en el Fondo pues se encontraba comprometido para asistir al IV Congreso Mundial de Sociología en Italia. ${ }^{33}$ Seis meses después, sin embargo, manejando su combi desde Nueva York con su esposa Yaroslava y su pequeña hija Katie, Mills llegó a México a fines de enero para impartir el seminario "Liberalismo y marxismo" en la unam. Después de pasar tres días en la Ciudad de México se instalaron en Cuernavaca, en la casa de una vieja profesora de inglés. En una carta a su amigo Harvey Swados, Mills escribió:

31 Así tituló Cuevas un manifiesto publicado en México en la Cultura, el suplemento cultural de Novedades, en el que criticaba la aplastante hegemonía del muralismo y el nacionalismo cultural.

32 Zolov, “Expanding our Conceptual Horizons", pp. 47-73.

33 AHFCE, CWM, Carta de Mills a Orfila, 27 de julio de 1959, exp. 73/2112. A propósito de ese Congreso véase el artículo de Mac Lean y Estenós, "El Cuarto Congreso Mundial de Sociología”, pp. 321-329. 
“de México sólo esto: Más cornadas da el hambre que los toros". ${ }^{34}$ Después de varias semanas de estancia en el país, en las que se dio tiempo incluso para realizar con su familia un viaje a Oaxaca, Mills escribiría a propósito de México: "Katie [...] moralmente se ha topado con la realidad de México-que es la pobreza [...]" ${ }^{35}$ Podría decirse que también para él México representó, apenas después de algunos días en Brasil, un encuentro directo con la pobreza de lo que daba en llamar "el bloque de las naciones hambrientas".

A lo largo de cinco sesiones entre febrero y marzo de 1960 Mills debatió con un grupo en el que se encontraban, entre otros, el antropólogo Oscar Lewis, Matilde Rodríguez Cabo y quienes editaban el espectador. El seminario era presidido por González Casanova, quien desde la dirección de la Escuela Nacional de Ciencias Políticas buscaba vincular el estudio de las ciencias sociales con las discusiones que se daban en un contexto dominado por las luchas de liberación en Asia y África, y a partir de 1959, por la revolución cubana. ${ }^{36}$ Algunos de los intelectuales europeos más importantes serían invitados durante su gestión para impartir los Cursos de Verano e Invierno en la Escuela. ${ }^{37}$ En ese contexto, y de acuerdo a una nota periodística, Mills hablaría sobre la "decadencia de las izquierdas" pues estaba considerado como uno de los personajes que "encabeza el movimiento para dar una nueva doctrina y actuación eficaz a las izquierdas". ${ }^{38}$

\footnotetext{
34 En la misma carta la esposa de Mills contaba: "pasamos tres días miserables en la ciudad de México antes de decidir explorar Cuernavaca (rajaron el techo de nuestro VW)”. K. Mills y P. Mills (eds.), C. Wright Mills, p. 287.

35 K. Mills y P. Mills (eds.), C. Wright Mills, p. 288.

36 El seminario fue conducido en inglés y Mario Monteforte Toledo actuó como traductor. Excelsior (24 feb. 1960). Pozas, "Pablo González Casanova 1957-1965”, pp. 22-30.

37 Estrada, “Ciencias Políticas en los años sesenta”, pp. 95-102.

38 Excelsior (21 feb. 1960).
} 
En efecto, el profesor Mills abordó en el transcurso de las sesiones de trabajo lo que consideraba era el agotamiento del liberalismo y el anquilosamiento del pensamiento marxista. Desde fines de 1956, durante su estancia en Europa, se había propuesto escribir un libro con una revisión crítica del marxismo y una selección de textos clásicos, impulsado por la idea de ser una suerte de traductor de esa línea de pensamiento en Estados Unidos. ${ }^{39}$ A fines de 1959 se encontraba de lleno dedicado a ese proyecto, por lo que seguramente cuando fue invitado a la UNAM esa fue la temática escogida. El seminario le permitió entonces discutir las ideas de su nuevo libro.

Durante su estancia en México Wright Mills asistió a reuniones y tertulias, alguna de ellas en la casa de Orfila o en las instalaciones del Fondo. De acuerdo con González Pedrero: "Después de cada sesión solíamos conversar con Wright Mills: un hombre muy sencillo, trabajador, demócrata culto [...] Pablo González Casanova, Carlos Fuentes y yo nos hicimos muy amigos de Wright Mills". ${ }^{40}$ El grupo coincidía con los planteamientos del sociólogo, sobre todo en cuanto a la relevancia de los intelectuales y los científicos sociales como actores políticos comprometidos, como conciencia crítica y vanguardia posible del cambio social.

Cuba sería un tema recurrente en esas conversaciones. Como señaló González Casanova en una entrevista, a raíz de la revolución cubana "un nuevo fervor sacudió a las universidades latinoamericanas". ${ }^{41}$ Tanto González Pedrero como Fuentes habían expresado su compromiso con la revolución prácticamente desde que los revolucionarios entraron a La Habana. González Pedrero se encontraba en la ciudad a fines de diciembre de 1958 con su esposa, la escritora cubana Julieta Campos, y pudo

${ }^{39}$ K. Mills y P. Mills (eds.), C. Wright Mills, p. 217.

40 Testimonios y conversaciones, p. 100.

41 Pozas, "Pablo González Casanova”, p. 27. 
presenciar los últimos días del gobierno de Batista, así como la adhesión popular a la Revolución. Para él no quedaba duda: "existe una identificación plena y rotunda entre la nación cubana y su revolución libertaria. Decir pueblo de Cuba y revolución, en estos momentos, es decir la misma cosa". ${ }^{42}$ Meses después sería de los primeros en publicar un libro sobre la revolución, resultado de una serie de conferencias impartidas en la Escuela de Ciencias Políticas. ${ }^{43}$ Carlos Fuentes por su parte, también desde La Habana, escribiría en los primeros días de enero de 1959 en favor de los fusilamientos que los revolucionarios llevaban a cabo en esos días: "Fidel Castro está haciendo lo que Madero debió hacer: liquidar desde la base la herencia de la dictadura". ${ }^{4}$ En julio de ese año sería testigo del histórico desfile en el que Fidel Castro y Lázaro Cárdenas celebraron juntos el triunfo del Movimiento 26 de Julio y la confluencia de ambas revoluciones. En la crónica que escribió para “México en la Cultura” Fuentes señalaba como objetivo de la revolución el impulsar "la transformación de una estructura económica colonialista y semifeudal en otra de democracia social, producción diversificada e industrialización nacional, cuyo presupuesto y base es la Reforma Agraria”. Y concluía: “[...] pasa ante mis ojos todo un pueblo, que no es sólo de Cuba. Es de México, es de Hispanoamérica. Nuestra lucha es la misma: esta es la más clara lección de las horas en Cuba". ${ }^{45}$

Las discusiones que Mills sostuvo en México con “los espectadores" quedaron plasmadas en una entrevista que se publicó primero en versión abreviada en el número 8 de esa revista, que habría de ser el penúltimo en salir a la luz: "Diez Ideas de Wright Mills” contenía los puntos esenciales de la conversación

${ }^{42}$ Rosa Castro, "Entrevista con Enrique González Pedrero", en México en la Cultura (ene. 1959).

43 González Pedrero, La Revolución Cubana.

${ }_{44}$ México en la Cultura (ene. 1959).

${ }^{45}$ México en la Cultura (9 ago. 1959). 
que sus editores sostuvieron con el sociólogo en el marco de su visita a la UNAM. Los temas planteados eran la crisis de la izquierda "tradicional”, la Guerra Fría y la situación de los países subdesarrollados. ${ }^{46}$ Los derechos de la versión ampliada fueron cedidos a Cuadernos Americanos para su difusión en México y América Latina.

En su edición de mayo-junio Cuadernos Americanos publicó la versión completa de la entrevista realizada por Fuentes, González Pedrero, Flores Olea y García Terrés bajo el título "Izquierda, subdesarrollo y Guerra Fría". Los editores mencionaban que, independientemente "de las divergencias que suscitan estos conceptos en los medios democráticos latinoamericanos, hemos pensado que es importante conocer el pensamiento de uno de los más autorizados voceros de la inteligencia norteamericana contemporánea". La transcripción completa de las preguntas con el nombre de quien las realizó permitían seguir en el texto los matices de la discusión con Mills que, como lo anunciaba el título, giró en torno a los procesos de industrialización de los países subdesarrollados en el contexto de la Guerra Fría, la relación entre Estados Unidos y América Latina como un factor determinante para las problemáticas del desarrollo en la región, y el papel de la izquierda y los intelectuales en estos procesos. ${ }^{47}$

Para Mills la victoria fundamental en la Guerra Fría, más allá de lo bélico, consistía en imponer el modelo de industrialización a los países subdesarrollados o "preindustriales". Sin dejar de lado el paradigma industrializador, el tema era si este se llevaría a cabo de acuerdo al modelo capitalista o al del socialismo soviético con sus consecuencias autoritarias. En esa coyuntura la nueva izquierda debía formular una alternativa, una tercera vía de desarrollo que trascendiera el modelo de las dos grandes potencias.

\footnotetext{
46 el espectador, 8 (abr. 1960).

47 Cuadernos Americanos, 3 (mayo-jun. 1960).
} 
América Latina estaba condicionada regionalmente por los Estados Unidos, pero, de acuerdo con Mills, el contrapeso de la URSS, China y los demás países socialistas ofrecía una mayor capacidad de independencia económica y negociación comercial. Frente a la insistencia de González Pedrero y Fuentes en la hegemonía económica estadounidense que se alimentaba de las economías exportadoras de materias primas e imponía condiciones políticas y militares, Mills contraponía su escepticismo sobre la ecuación imperialismo-subdesarrollo. Para el sociólogo las dificultades del desarrollo en América Latina tenían más que ver con las élites locales que con Estados Unidos, argumento que sería rebatido por sus interlocutores con el ejemplo de Guatemala y lo que empezaba a suceder en Cuba. Aunque Mills estaba de acuerdo con ellos en la posibilidad de que se ahondaran las represalias económicas contra la isla, insistía en que Estados Unidos no respondería a esa revolución como lo había hecho antes en Nicaragua o en Guatemala porque la existencia del contrapeso soviético se lo impedía. Finalmente, en relación con el papel de los intelectuales, Mills señalaba que, por lo menos en los países subdesarrollados, eran ellos los responsables de impulsar las transformaciones sociales por la influencia que ejercían en sus sociedades. Como parte de ese proceso los intelectuales debían impulsar la expropiación del aparato cultural, tarea ineludible para una nueva izquierda.

Poco después de que apareciera la entrevista en Cuadernos Americanos Carlos Fuentes envió el texto a Don Allen, quien a su vez se lo mandó a Fred Jordan, ambos coeditores de Evergreen Review, con la intención de que se publicara en inglés. Después de recibir una primera versión del texto traducido Mills le escribió a Jordan para darle sus comentarios sobre la traducción que le había enviado para que la revisara. En la carta Mills le decía que no conocía la versión en español pues ni siquiera leía el idioma. Por esa razón le solicitaba que se añadiera una nota en la que se dijera que esta era la única versión revisada y aprobada 
por él. En la traducción del texto que le habían enviado "me hacen decir prácticamente que soy un leninista. Por supuesto que nunca lo he sido ni soy nada parecido". ${ }^{48}$ Muy probablemente se refería a este párrafo: "Los intelectuales se colocan en la extrema izquierda revolucionaria precisamente cuando confluyen las siguientes circunstancias: subdesarrollo económico, pobreza abismal y gobierno autocrático [...] Para países con esas características, el leninismo es la única respuesta que conozco". ${ }^{49} \mathrm{~A}$ diferencia de la publicación en Cuadernos Americanos, en la edición en inglés los autores de las preguntas no eran mencionados y tanto las preguntas como las respuestas fueron editadas y resumidas. La frase sobre "el leninismo" desapareció. ${ }^{50}$

\section{“CON UN ABRAZO REVOLUCIONARIO”}

En la primavera de 1960 Mills se llevó de regreso a Nueva York el entusiasmo que la revolución cubana generaba entre los intelectuales mexicanos. En palabras de Dan Wakefield, en ese momento su colaborador y amigo, las frecuentes preguntas que había recibido sobre su postura personal y la de su país frente a Cuba "así como el interés predominante de los intelectuales latinoamericanos en la cuestión incitaron su deseo de ir ahí y escribir sobre eso". ${ }^{11}$ Aunado a ello, al llegar a la ciudad, tal como lo ha analizado Rafael Rojas, esta era un hervidero de apoyo a la revolución..$^{52}$ Después de un muy anticipado viaje a la URSS que

48 ILHTS, Carta de Mills a Fred Jordan, 3 de noviembre de 1960, box 120, folder 1. Esta carta forma parte de una colección de documentos personales de Mills que Irving Louis Horowitz integró como parte del acervo I. L. Horowitz Transaction Archives, depositado en Penn State University Libraries. Para saber cómo y por qué sucedió esto véase el artículo de Summers “The Epigone’s Embrace", pp. 107-124.

${ }^{49}$ Cuadernos Americanos, 3 (mayo-jun. 1960), p. 65.

${ }^{50}$ Evergreen Review, 5: 16 (ene.-feb. 1961).

${ }^{51}$ K. Mills y P. Mills (eds.), C. Wright Mills, p. 12.

52 Rojas, Fighting over Fidel. 
realizó entre abril y mayo y gracias a los oficios del periodista Robert Taber, quien había entrevistado a Fidel Castro en 1957 para un documental que se transmitió en la cadena de televisión CBS, en julio Mills se entrevistó con Raúl Roa Kourí, representante de Cuba ante la onu, en busca de una invitación a la isla. ${ }^{53}$ Roa le platicó que Fidel leía y discutía en la Sierra Maestra La élite del poder, hecho que sin duda alimentó el ego de Mills y lo incitó aún más a viajar a Cuba. Curiosamente, cuando un año antes, el 15 de abril de 1959, el propio Fidel estuvo en un seminario en la Universidad de Columbia, el profesor Mills se encontraba en Stanford dando una conferencia sobre "la decadencia de la izquierda". ${ }^{54}$ En ese momento la revolución cubana todavía no era de su interés.

A su regreso de la Unión Soviética Mills le envió a Carlos Fuentes el texto "The Balance of Blame" para que lo publicara en español “en tu revista”. Le interesaba sobre todo, y así se lo hizo notar al propio Fuentes, que se pudiera leer en Cuba. Aunque no sabía a dónde enviarlo pensaba que les podría interesar. ${ }^{55}$ Semanas después, en una carta dirigida a Hans Gerth en la que le comentaba que viajaría a la isla, explicaba las razones de su viaje: "Tengo que ir y averiguar algunas cosas por mi cuenta antes de escribir lo que siento que necesito escribir sobre el lugar”. Le mencionaba también lo que Roa Kourí le había platicado, que “ $;$ Castro se sentaba en Oriente leyendo y discutiendo con su banda The Power Elite! Dios mío, y este tipo de cosa está ocurriendo más y más con ese libro $[\ldots]$ ”. ${ }^{56}$

53 K. Mills y P. Mills (eds.), C. Wright Mills, p. 304.

54 The Politics of Truth, p. 213. A propósito de la visita de Fidel Castro a la Universidad de Columbia véase SERvín, "Frank Tannenbaum entre América Latina y Estados Unidos en la Guerra Fría”, pp. 64-65.

55 CFP, Carta de Mills a Fuentes, 9 de junio de 1960, box 116, folder 13. El texto se publicó en The Nation el 18 de junio de 1960. La Revista de la Universidad publicó la versión en español en diciembre de ese año.

56 K. Mills y P. Mills (eds.), C. Wright Mills, p. 304. 
Entre el 8 y el 24 de agosto Mills viajó a Cuba en un recorrido organizado por Taber y Roa. Como lo expresara a Gerth, la intención original y explícita del viaje era conocer de cerca la revolución que generaba el entusiasmo de la izquierda internacional para poder expresar su opinión sobre ella. De esta manera Mills ingresaba al grupo de intelectuales estadounidenses que en algún momento se asumieron como intérpretes de la condición revolucionaria latinoamericana en Estados Unidos. Si en los años veinte la revolución mexicana había atraído a una cauda de observadores, en los sesenta era Cuba y su revolución la que despertaba el interés de quienes se asumían como intermediarios culturales entre América Latina y su país. Como ellos, el profesor Mills también se propondría a su regreso y desde su posición como intelectual crítico influir en la política exterior estadounidense hacia Cuba y América Latina.

A lo largo de una frenética estancia de dos semanas Mills se entrevistó con diversos personajes, entre ellos el propio Fidel, con quien grabó horas de conversaciones, además del Che y otros personajes de la revolución. El hecho de que la agenda estuviera organizada por el gobierno cubano no pareció importarle mucho en términos de lo que eso implicaría para acercarse de lleno y objetivamente a lo que sucedía en Cuba. ${ }^{57}$

Al regresar a Nueva York Mills trabajó febrilmente en la escritura de Listen, Yankee. Quería por medio de su libro dar a conocer al público estadounidense lo que realmente ocurría en Cuba ante la desinformación y la propaganda anticomunista con la que se abordaba el tema en Estados Unidos. En cierto sentido este libro era la mejor expresión de lo que Mills había desarrollado en otros textos y resultado de un compromiso personal por participar en la discusión pública:

57 A propósito de la estancia de Mills en Cuba véanse Landau, " $\mathrm{C}$. Wright Mills. The Last Six Months", pp. 46-47, y Treviño, C. Wright Mills and the Cuban Revolution. 
el compromiso del intelectual como actor social cuya obligación ética consistía en analizar las circunstancias para ofrecer una visión crítica a la sociedad, haciendo del conocimiento una acción política que pudiera generar conciencia social. Listen, Yankee se proponía expresamente llegar a un público masivo para ofrecerle "la verdad" de la revolución, para "ir a la raíz" de la coyuntura cubana con el ánimo de que ello pudiera incidir en la postura del gobierno estadounidense frente a Cuba. Con un estilo narrativo en el que Mills "desaparecía” como autor para cederles la palabra a los cubanos, quienes de esa manera explicaban su revolución, el sociólogo de nuevo salía de la academia para entrar de lleno al ámbito del público masivo. La primera edición se publicó a fines de noviembre y muy pronto se vendieron miles de ejemplares. Desde el primer momento el libro generó un intenso debate en la opinión pública en torno a la revolución cubana. ${ }^{58}$

En los primeros días de octubre Mills le escribió a Fuentes para platicarle del libro, "escrito en estado 'febril' [...] una especie de gran desahogo". Quería que el libro se publicara en español lo más pronto posible y que fuera traducido "con verdadera emoción y gracia”. Además de preguntarle sobre un editor - pensaba que el Fondo sólo distribuía en librerías y él quería el libro "en estaciones de tren"-, Mills le proponía que fuera el propio Fuentes, tal vez en colaboración con "Gonzales", quien hiciera la traducción. "Sería maravilloso si así fuera" ${ }^{59}$ Carlos Fuentes se comunicó con Orfila y éste a su vez le escribió a Mills para decirle que tenía "un interés especial" en el libro. Pensaba que podría editarlo en la Colección Popular, con un tiraje inicial de 15 a 20000 ejemplares y un número adicional para distribuir en Cuba. Orfila terminaba su carta mencionando

${ }^{58}$ Rojas, Fighting over Fidel, cap. 4.

${ }^{59}$ CFP, Carta de Mills a Fuentes, s/f, box 116, folder 13. 
el gusto que le generaba difundir un nuevo libro de Mills y contribuir así a la causa de la revolución cubana. ${ }^{60}$

Pocos días después Mills le escribió de nuevo a Fuentes para decirle, primero, que era precisamente eso lo que él quería, una edición masiva de libros baratos. Pero, le comentaba, si lo hacían, debía ser un proceso editorial muy rápido. En segundo lugar, debían tener presente que "no conozco la actitud del gobierno cubano hacia el libro, especialmente mi manejo franco sobre el tema del comunismo. En Cuba el tema es arriesgado. Por supuesto el libro es una fuerte declaración a favor de la revolución”. Mills le comentaba también que participaría en un debate organizado por la cadena de televisión NBC sobre la política de Estados Unidos hacia América Latina, mismo que se vería en todo el país la noche del sábado 10 de diciembre. Su contrincante en el debate era Adolf A. Berle Jr., reconocido latinoamericanista, exembajador en Brasil y quien a partir de 1961 sería asesor del presidente Kennedy para asuntos de América Latina. Lo que había empezado como un "pequeño panfleto", le escribía Mills a Fuentes, se estaba convirtiendo en algo grande: "Sabrá Dios qué pase dada la monolítica opinión y prensa anti Castro en Estados Unidos. Será fascinante verlo". ${ }^{61}$

Poco más de un mes después Mills le escribió a Orfila respondiendo a sus sugerencias editoriales:

Le agradezco que me pida escribir un prefacio para el lector latinoamericano pero no puedo hacerlo. Como verá cuando lea Listen, Yankee, he escrito de manera que sea pertinente tanto para latinoamericanos como para norteamericanos. No he estado en Cuba desde agosto y por tanto no tengo nada nuevo que añadir. Planeo ir en enero si es que puedo. Lo que sí espero que pueda resolver es

60 AHFCE, CWM, Carta de Orfila a Mills, 15 de octubre de 1960, exp. $73 / 2112$.

${ }^{61}$ K. Mills y P. Mills (eds.), C. Wright Mills, p. 317. 
que la edición salga rápido. No creo que “caduque” tan rápido pero sí siento que es muy urgente. Debo añadir que estoy muy contento de que sea usted quien esté a cargo de la edición en español.62

El 6 de diciembre Orfila se comunicó otra vez con Mills para decirle que la traducción la haría González Pedrero, a quien ya conocía de su viaje a México. De nuevo terminaba su carta señalando su satisfacción por contribuir desde el Fondo a la difusión de "su excelente material sobre Cuba, a cuya revolución estamos contentos de prestar este servicio" ${ }^{63}$ En alguna entrevista comentaría González Pedrero:

Naturalmente nos lo ofrecieron a Julieta y a mí para traducirlo: entonces ella conservaba su nacionalidad cubana y yo conocía bien el proceso revolucionario de Cuba. Digamos que teníamos bastantes experiencias y conocimientos como para aproximarnos desde la mejor perspectiva a la obra de Mills. ${ }^{64}$

Mientras se daba este intercambio, las críticas a Listen, Yankee en los medios estadounidenses eran brutales. Aunado a ello Mills se enfrentaba al creciente acoso del FBI y los grupos anticastristas. ${ }^{65}$ Durante una visita de Carlos Fuentes a su casa en Nueva York recién publicado el libro, Mills le comentó que había recibido amenazas:

'Recibí un anónimo', me dijo Mills. 'Dice que cuide a mi niña de un accidente si sigo defendiendo a Cuba' [...] Las agencias inquisitoriales del gobierno norteamericano estaban investigando a Wright.

62 AHFCE, CWM, Carta de Mills a Orfila, 25 de noviembre de 1960, exp. $73 / 2112$.

${ }^{63}$ AHFCE, CWM, Carta de Orfila a Mills, 6 de diciembre de 1960, exp. $73 / 2112$.

${ }^{64}$ Testimonios y conversaciones, p. 101.

${ }^{65}$ K. Mills y P. Mills (eds.), C. Wright Mills, pp. 319 y ss. 
Recibía telefonazos amenazantes de los "Tigres" de Masferrer y otras organizaciones contra-revolucionarias cubanas. ${ }^{66}$

Pese al hostigamiento y las descalificaciones el éxito editorial del libro había sido de tal magnitud que el debate con Berle era esperado con gran anticipación. Consciente de las dificultades de enfrentar a un experto en asuntos latinoamericanos y de sus propias deficiencias en el conocimiento de la región, aunadas a lo que él asumía como una responsabilidad personal por ofrecer una visión alternativa ante una audiencia calculada en 20 millones de televidentes, Mills llevaba varias semanas preparándose con jornadas exhaustivas de trabajo y estudio sobre América Latina y su relación con Estados Unidos. El cansancio y la presión del debate se sumaron al entorno adverso que ya padecía y una noche antes de presentarse en la televisión Mills sufrió un infarto fulminante que lo puso al borde de la muerte. ${ }^{67}$

El 15 de diciembre Yaroslava Mills le escribió una breve nota a Fuentes en la que le informaba sobre la condición médica de su esposo, quien, aunque ya estaba fuera de peligro, debería permanecer en cama por lo menos uno o dos meses y hasta entonces estaría en condiciones de trabajar. Era importante, le decía, que Fuentes se comunicara con Orfila para decirle, primero, que la revista cubana Bobemia había publicado sin autorización una versión resumida del libro y que debía cuidar los derechos en español que había adquirido. Sobre todo, le insistía, era fundamental que el libro se publicara pronto:

Como probablemente percibes, Cuba y América Latina son tremendamente importantes para Wright, sé que él pensó que este librito podría ser importante en América Latina y que lo escribió

66 Fuentes, Casa con dos puertas, p. 103. Agradezco a Mauricio Tenorio esta referencia.

${ }^{67}$ Landau, “C. Wright Mills. The Last Six Months”, p. 47. 
tanto para Orfila como para cualquier editor en Estados Unidos. En la edición de bolsillo por acá ya llevamos un tiraje de un cuarto de millón. ¡Venceremos! ${ }^{68}$

Pocos días después, enterado del infarto por Fuentes, Orfila le escribió a Mills:

Creo y deseo que su estado sea transitorio debido a un exceso de trabajo y también debido a las muchas preocupaciones causadas a usted por sus malos compatriotas que lo han atacado por su magnífica, extraordinaria, valiente lucha por la Libertad y la Justicia. Leyendo en voz alta su LISTEN YANKEE con mi esposa, quedamos conmovidos por la grandeza que muestra en su cabal comprensión de la raíz de los problemas de nuestro continente. Es la esencia exacta de la Revolución Cubana. Quiero expresarle la profunda satisfacción que siento de poder difundir su bello mensaje al mundo de habla hispana. ${ }^{69}$

Mientras Mills convalecía en terapia intensiva, el 17 de diciembre Saturday Review publicó una reseña de Listen, Yankee firmada por el periodista Jules Dubois, decano de los corresponsales en América Latina y quien también había publicado un libro sobre la revolución..$^{70}$ Entre muchas otras cosas Dubois acusaba a Mills de hacerle el juego a los comunistas que se habían apoderado de Cuba y de repetir "como perico" las "absurdas acusaciones” de que la prensa estadounidense había sido injusta con Castro y con Cuba y que ningún periodista sabía cómo

${ }^{68}$ CFP, Carta de Yaroslava Mills a Fuentes, 15 de diciembre de 1960, box 116, folder 13. De acuerdo a las hijas de Mills, Fuentes lo visitó en su casa durante su convalecencia después del infarto. K. Mills y P. Mills (eds.), C. Wright Mills, p. 355.

69 AHFCE, CWM, Carta de Orfila a Mills, 29 de diciembre de 1960, exp. 73/2112. El original de la carta está en inglés. La traducción es mía.

70 Dubois, Fidel Castro. 
reportar el impacto de una revolución. Dubois defendía a las "sensatas y progresistas empresas estadounidenses", cuyas inversiones, aliadas a las de las empresas nacionales en América Latina, eran el mejor antídoto contra el comunismo. Terminaba su reseña señalando que no sería sorprendente que Moscú anunciara la publicación del libro en ruso y otros "idiomas del bloque soviético". ${ }^{71}$

Pocos días después Mills recibió una carta de Fuentes en la que, además de expresarle sus buenos deseos por su pronta recuperación, le transmitía su enojo por esa reseña:

Tú sabes cuánto todos te admiramos y te queremos, no sólo como la principal voz intelectual de Estados Unidos sino sobre todo como ser humano y como amigo [...] ¿Qué?, ¿ estos tipos no pueden ver lo que está escrito en la pared? ¿No pueden escuchar y entender la verdad cuando se dice con tanto valor y honestidad como lo has hecho en tu poderosa declaración?

Con la carta Fuentes le enviaba una copia del texto que querían publicar en Estados Unidos en respuesta a esa reseña. Y terminaba diciéndole: "siento, Wright, que tu libro está generando una verdadera relación entre el pensamiento honesto norteamericano y la intelectualidad de América Latina. Alíviate pronto: tenemos muchas cosas que hacer juntos". ${ }^{72}$

En efecto, el 21 de enero el mismo semanario publicó una carta seguramente escrita por Fuentes y firmada por "Los amigos de C. Wright Mills en México", Fernando Benítez, Carlos Fuentes, Arnaldo Orfila Reynal, Víctor Flores Olea, Enrique González Pedrero, Jaime García Terrés, Francisco López Cámara y Pablo González Casanova, en la que acusaban a Dubois de

${ }^{71}$ Saturday Review (17 dic. 1960).

72 ILHTS, Carta de Fuentes a Mills, 27 de diciembre de 1960, box 120, folder 2. El original de la carta está en inglés. La traducción es mía. 
reseñar el libro con cinismo y mala fe. Escrita en el mismo tono narrativo del libro de Mills y dirigida también a "los yankees”, enumeraban los logros de la revolución, el apoyo popular a los dirigentes revolucionarios y les pedían no dejarse engañar:

¿Así que Dubois piensa que la destrucción de las 'sensatas y progresistas empresas estadounidenses' causarían un 'deterioro en el nivel de vida' de los países latinoamericanos? Pregúntale al recolector de plátanos en Guatemala, al minero peruano, al campesino colombiano... Serás apedreado. Te escupirán. Dubois no nos engañará. Está tratando de engañarte a ti. Por favor, Yanqui, no te dejes engañar.

Terminaban la carta protestando contundentemente en contra de las "críticas falaces" de Jules Dubois y defendiendo con la misma contundencia a Mills, a quien consideraban "la verdadera voz del pueblo norteamericano por su honestidad, su valor y su conciencia acerca de las nuevas fuerzas del mundo subdesarrollado". ${ }^{73}$

Obligado a guardar reposo, en cuanto pudo Mills se comunicó con Fuentes a través de un dictado para agradecerle la publicación de la "maravillosa carta”. También le comentaba que el editor de Harper's quería un artículo del escritor sobre "el clima intelectual de América Latina”. Era una buena oportunidad, le decía Mills, para que el medio millón de lectores de la revista tuvieran una idea de América Latina desde el punto de vista de "nuestra nueva izquierda”. Le sugería que contactara a Carl Brandt, su agente literario, quien se encargaría del asunto. De hecho, le decía, Brandt debería ser su agente en Estados Unidos pues "en este momento toda clase de escritores mexicanos, así como de otros países latinoamericanos (¡por lo menos de fuera de Cuba!), pueden encontrar recepción”. Mills terminaba la carta con la palabra “¡Venceremos!” y en una postdata mencionaba

73 Saturday Review (21 ene. 1961). 
que ojalá Orfila enviara copias de la edición en español “a la gente de América Latina en las Naciones Unidas". ${ }^{74}$ En carta separada el propio Brandt le explicaba a Fuentes que Wright Mills le había dictado por teléfono la comunicación a su secretaria para que se la hicieran llegar. ${ }^{75} \mathrm{El}$ escritor mexicano siguió la sugerencia de Mills y, como es bien sabido, en los años siguientes Carl Brandt sería un reconocido agente en lengua inglesa del llamado boom literario latinoamericano. ${ }^{76}$ Se abría de esta manera una nueva vertiente para Carlos Fuentes como intérprete de América Latina en Estados Unidos. ${ }^{77}$

El 20 de marzo de 1961 el Fondo publicó la primera edición de Escucha, yanqui en la nueva colección "Tiempo presente" con un tiraje inicial de 20000 ejemplares que se agotaron en un mes. En mayo se imprimió la segunda edición, de otros 20000 ejemplares, que también se vendieron muy pronto. ${ }^{78}$ Desafortunadamente, le explicó Orfila a Mills, no había sido posible distribuirlo en Cuba por los problemas económicos en la isla y el racionamiento de las importaciones. Esperaba que la situación se regularizara muy pronto. En todo caso, le decía, ojalá estuviera contento "de haber beneficiado a toda Latinoamérica con su libro". ${ }^{79}$ Justo un par de días antes de que apareciera la primera edición en español, Mills les escribía a sus padres que "cada

\footnotetext{
${ }^{74}$ K. Mills y P. Mills (eds.), C. Wright Mills, p. 322.

75 CFP, Carta de Carl D. Brandt a Carlos Fuentes, 12 de enero de 1961, box 89 , folder 34.

76 Véase, por ejemplo, Donoso, Historia personal del "boom", pp. 59-61.

77 La dimensión de Carlos Fuentes como intelectual público e intermediario cultural entre América Latina y Estados Unidos rebasa los límites de este artículo. Entre la amplia bibliografía sobre el tema pueden consultarse los textos de Aguilar Rivera, La sombra de Ulises, cap. 3; Tenorio Trillo, “A Lost Opportunity”; Servín, "Frank Tannenbaum entre América Latina y Estados Unidos en la Guerra Fría”, pp. 70 y ss., y ZoLov, The Last Good Neighbor, cap. 6 [en prensa].

78 AHFCE, CWM, Carta de Orfila a Mills, 20 de mayo de 1961, exp. 73/2112.

79 AHFCE, CWM, Carta de Orfila a Mills, 6 de marzo de 1961, exp. 73/2112.
} 
embajador estadounidense en cada país latinoamericano tendrá que debatir con mi libro y contestarlo. Y así es exactamente como deberá ser porque estos yanquis idiotas están mal". ${ }^{80}$

El 17 de abril inició el intento de invasión a Cuba organizado por el joven gobierno de John F. Kennedy. El profesor Mills se encontraba a unos días de viajar con su familia a Europa para pasar un año con licencia de la Universidad y en busca de recuperarse de sus padecimientos cardiacos. Ante la preocupación de sus padres, Mills les escribió:

He estado enfermo y lleno de rencor y también en plena pelea contra las actividades criminales del gobierno de Kennedy contra Cuba. Mi madre entenderá esto pues, aunque nunca ha visto Cuba, sé que tiene, como su ideal del ser humano, a los hombres y las mujeres de México. Los cubanos son mis mexicanos". Firmaba la carta "con un abrazo revolucionario", así, en español. ${ }^{81}$

A fines de mayo Orfila se comunicó con Mills, quien se encontraba en Londres, para comentarle que estaban preparando la tercera edición del libro puesto que las dos anteriores estaban por agotarse, lo que entre paréntesis representaba un éxito editorial. Dados los acontecimientos de abril, pensaba que era importante incluir un prefacio o un apéndice que se refiriera a "la reciente agresión": "Sé ya que usted está tan conmovido como yo lo estoy por estos dramáticos eventos". ${ }^{82}$ En respuesta, el 6 de junio Mills le escribió desde Suiza para decirle que se

${ }^{80}$ K. Mills y P. Mills (eds.), C. Wright Mills, p. 326.

${ }^{81}$ La madre de Mills había crecido en un rancho en Texas y su cercanía con los mexicanos era descrita así por él: "Mi madre habló español antes que inglés; fue criada en un rancho por mexicanos y los quiso de verdad -no como señora gringa, sino como un ser humano ama a otro-. Para ella, creo, los mexicanos siempre han conformado su modelo ideal del Ser Humano”. K. Mills y P. Milus (eds.), C. Wright Mills, p. 313.

82 AHFCE, CWM, Carta de Orfila a Mills, 20 de mayo de 1961, exp. 73/2112. 
encontraba trabajando en un apéndice en la forma de "una tercera nota al lector". Le decía también: "confidencialmente, tengo la intención de regresar a Cuba a la mitad del invierno, tal vez volando desde Praga, ya que no regreso a Estados Unidos sino hasta septiembre de 1962 cuando más pronto". ${ }^{83}$ Pocos días antes, en efecto, Yaroslava Mills les había enviado una postal a sus suegros comentando la posibilidad de verlos en Navidad en México pues tal vez irían a Cuba a trabajar por esas fechas. ${ }^{84} \mathrm{Or}$ fila le contestó a Mills el 22 de junio para decirle que esperaban con mucho interés su texto para incluirlo en la tercera edición. Las dos anteriores estaban ya prácticamente agotadas, lo que representaba un éxito singular para el Fondo. A propósito de su posible viaje a Cuba, Orfila le decía que seguramente le ayudaría en su recuperación y “fortalecerá su espíritu”. 85

Desde el primer momento el intercambio entre autor y editor resultó notable por el compromiso explícito que ambos sentían con la revolución cubana. Orfila le agradecía haber escrito el libro y por ende colaborado en la defensa de Cuba y América Latina, y Mills por su parte le agradecía haberle abierto las puertas del mundo hispanohablante. Casi en todas sus cartas le expresaría a Orfila su intención de regresar a Cuba.

\section{"en cierta forma lo extraño"}

La publicación de Escucha, yanqui se dio en el contexto de la movilización que la izquierda realizaba a favor de Cuba y que, tal como lo expresaran claramente "los espectadores" en 1959, se había articulado con la crítica al régimen que se legitimaba en la anquilosada revolución mexicana. El 5 de marzo de 1961, poco antes de que la primera edición de Escucha, yanqui apareciera en

83 AHFCE, CWM, Carta de Mills a Orfila, 6 de junio de 1961, exp. 73/2112.

${ }^{84}$ CWMP, Postal de Yaroslava Mills a Mr. and Mrs. C. G. Mills, 3 de junio de 1961, box 4B353.

85 AHFCE, CWM, Carta de Orfila a Mills, 22 de junio de 1961, exp. 73/2112. 
librerías, se llevó a cabo en la Ciudad de México la Conferencia Latinoamericana por la Soberanía Nacional, la Emancipación Económica y la Paz, con la presencia de 16 delegaciones latinoamericanas, además de representantes de China, la Unión Soviética y varios países africanos. Se trataba del primer esfuerzo de reagrupamiento de una izquierda progresista latinoamericana impulsado por la revolución cubana y los movimientos de liberación nacional y que encabezaba el expresidente Lázaro Cárdenas. En los meses siguientes, acompañado por un grupo de delegados, el expresidente realizó un intenso recorrido por el país con la intención de conformar organizaciones que se sumaran a los objetivos de la Conferencia. El 4 de agosto esta dio paso a la fundación del Movimiento de Liberación Nacional (MLN), una nueva coalición de los grupos que integraban a la izquierda mexicana, que se comprometían a la defensa de Cuba y al impulso de la renovación democrática del proyecto social de la revolución mexicana. En el MLN habrían de congregarse los cardenistas junto con la izquierda partidaria y un nutrido grupo de intelectuales entre los que destacaban los amigos de Mills, Carlos Fuentes, Enrique González Pedrero y Víctor Flores Olea. ${ }^{86}$

En ese contexto Escucha, yanqui tuvo un fuerte impacto editorial tanto en México como en otros países de América Latina. La defensa que hacía Mills del proceso cubano en plena Guerra Fría, su fama como un agudo crítico de la élite estadounidense que se leía desde 1957 en La élite del poder, así como el peculiar estilo narrativo del texto, escrito en la voz de un revolucionario cubano, contribuyeron a la popularidad de Escucha, yanqui. Si

\footnotetext{
86 A propósito del MLn puede consultarse entre otros Beltrán Villegas, "El MLN: historia de un recorrido hacia la unidad (México 1957-1967)"; SERvín, "Algunas ramas de un árbol frondoso", pp. 81-96; IвER, Neither Peace nor Freedom, cap. 5; Illades, La inteligencia rebelde; Keller, Mexico's Cold War; URÍAs HorCasitas, "Alianzas efímeras: izquierdas y nacionalismo revolucionario”, pp. 1205-1252, y Zolov, The Last Good Neighbor.
} 
en Estados Unidos Listen, Yankee había sido fuertemente criticado, en México el libro sería recibido con aceptación e interés. La voz de Cuba replicada por Mills se transformó en la voz de Mills como la verdadera voz de Norteamérica, la verdadera voz del pueblo estadounidense que se oponía a la intervención militar y las presiones económicas contra la isla. Muy pronto Escucha, yanqui se convirtió en lectura obligada de la naciente "nueva izquierda" latinoamericana, que encontraba en la revolución cubana una "tercera vía", un experimento nacionalista y antiimperialista que rompía no sólo con el colonialismo estadounidense sino también con la vieja izquierda estalinista. Tal y como ocurriera en Estados Unidos, si bien en México Mills ya era conocido por sus libros y sus publicaciones en la Revista de la UNAM y en Cuadernos Americanos, ambas con un público primordialmente universitario, Escucha, Yanqui lo hizo popular. No sólo los intelectuales y los académicos leyeron su libro.

El 14 de julio Mills le envió a Orfila el borrador del apéndice para la tercera edición, que estaba escrito en la forma de una serie de preguntas. Le comentaba que podía usar la respuesta a la tercera pregunta que había cortado del manuscrito como material publicitario en alguna revista. Le agradecía también que pudiera encargarse de que "los cubanos" recibieran una copia de la nueva edición. Finalmente le adelantaba que el apéndice tal vez no se publicaría en inglés pero esperaba que "a usted le guste". ${ }^{87}$

El material sugerido por Mills se publicó en Política, la revista dirigida por Manuel Marcué Pardiñas, que había empezado a circular desde mayo de 1960 y a la que se habían incorporado los editores que dieron por terminado el espectador desde esa fecha. ${ }^{88}$ Junto con ellos en Política confluyeron todas las voces del abanico que formaba en ese momento la izquierda mexicana

87 AHFCE, CWM, Carta de Mills a Orfila, 14 de julio de 1961, exp. 73/2112. Subrayado en el original.

${ }^{88}$ El último número fue el 9-10 con fecha mayo-junio 1960. A propósito de los textos de Carlos Fuentes publicados en Política véase Enríquez Perea, "En 
y que iban desde el lombardismo gobiernista y el cardenismo renovado hasta los sectores más radicalizados por la ola revolucionaria cubana. ${ }^{89}$

La tercera edición de Escucha, yanqui, con el apéndice "Escucha otra vez, yanqui; 1961", se empezó a distribuir el 21 de agosto y en menos de un mes se vendieron otros 10000 ejemplares. Esta vez se imprimieron 10000 más para distribuir en Argentina. Un mes después el Fondo puso en circulación $\mathrm{La}$ imaginación sociológica, la edición en español del libro publicado originalmente en 1959, que abriría a su vez nuevas perspectivas para los estudiosos de las ciencias sociales en el mundo hispanohablante..$^{90}$

A diferencia de sus estancias anteriores en Europa que lo habían llenado de entusiasmo y energía intelectual, en esta ocasión Mills padecía una suerte de "autoexilio" con una salud deteriorada. A fines de septiembre le escribía a Carlos Fuentes que hasta ese momento no había podido enfocarse en algún proyecto de trabajo y que estaba considerando quedarse un tiempo en Inglaterra. Era una decisión difícil. "Mientras tanto no hago nada más que existir". ${ }^{91}$ También a fines de septiembre desde Londres le comentaría a Orfila que le habían ofrecido una cátedra en una de las nuevas universidades que se formaban en Inglaterra y que se sentía tentado a aceptar la oferta, "para salir de la tensión de los Estados Unidos y dedicarme al trabajo aquí.

Politica: El periodismo militante de Carlos Fuentes”, Nexos, núm. 370, octubre 2008, pp. 65-72.

${ }^{89}$ Reynaga Mejía, La Revolución cubana en México. Urías Horcasitas, “Alianzas efímeras: izquierdas y nacionalismo", pp. 1205-1252. Keller, Mexico's Cold War.

90 AHFCE, CWM, Carta de Orfila a Mills, 11 de septiembre de 1961, exp. 73/2112. En julio de 1961 Cuadernos Americanos publicó "El investigador social y la política", capítulo de La imaginación sociológica que estaba por publicar el FCE.

${ }_{91}$ CFP, Carta de Mills a Fuentes, 23 de septiembre de 1961, box 116, folder 13. 
Pero todavía no sé lo que haré al respecto"..$^{92}$ El 19 de octubre Orfila le escribió para decirle que estaba muy interesado en conocer su decisión. Había pensado que "sería de gran ayuda para nosotros si decidiera trabajar en alguna de nuestras universidades latinoamericanas. Por ejemplo, en México, estarían felices si aceptara dar clases como profesor permanente y tal vez, desde aquí observaría los eventos mundiales desde una perspectiva diferente". En caso de que le interesara la propuesta Orfila le pedía que se lo hiciera saber para hablar concretamente "con la Escuela de Ciencias Políticas". 93

Un par de días antes de que Orfila le escribiera Mills envió una carta a sus padres en la que les mencionaba su decisión de regresar a Estados Unidos y a Columbia: "La decisión tiene menos que ver con los múltiples atractivos de Inglaterra que con el hecho de que mi argumento está en América y tiene que ser resuelto ahí. Lo llevas contigo y después de todo es tu maldita responsabilidad [...] Tal vez, no sé, pueda hacer una breve visita a México en la primavera. En cierta forma lo extraño". ${ }^{44}$ Días después, en su respuesta a la invitación de Orfila, Mills le repetía las razones en torno a su determinación de regresar a Estados Unidos:

La decisión tiene menos que ver con los atractivos de un profesorado aquí que con el hecho de que mi pequeño argumento empezó en los Estados Unidos y, para bien o para mal, tendrá que ser resuelto allá. Mientras tanto, por favor sepa qué agradecido estoy con usted por la sugerencia en su carta y por su expresión de amistad, que por favor tenga toda seguridad, es totalmente recíproca. ${ }^{95}$

92 AHFCE, CWM, Carta de Mills a Orfila, 23 de septiembre de 1961, exp. $73 / 2112$.

93 AHFCE, CWM, Carta de Orfila a Mills, 19 de octubre de 1961, exp. $73 / 2112$.

${ }^{94}$ K. Mills y P. Mills (eds.), C. Wright Mills, p. 338.

95 AHFCE, CWM, Carta de Mills a Orfila, 28 de octubre de 1961, exp. $73 / 2112$. 
Mientras ocurría este intercambio, Fuentes, por su parte, era informado por Carl Brandt de la decisión de Mills: "Wright ha decidido definitivamente regresar a casa, poco después del inicio de año. Tú sabes, tan bien como yo, qué difícil fue esta decisión para él, y sé que tú también lo admirarás tanto por ello como yo $[\ldots]]^{3}{ }^{96}$

A su regreso a Nueva York Mills se propuso retomar los proyectos que había dejado de lado cuando se metió de lleno al debate por Cuba. ${ }^{97}$ En México, mientras tanto, Carlos Fuentes trabajaba en la publicación del nuevo suplemento "La Cultura en México" en el semanario Siempre!. El apoyo a la revolución cubana que se leía cotidianamente en su antecesor, "México en la Cultura”, había provocado que le cerraran las puertas en el diario Novedades a fines de $1961 .^{98} \mathrm{Al}$ iniciar enero de 1962 Fuentes le escribió a Brandt para, entre otras cosas, pedirle que le solicitara a Mills una breve nota saludando al nuevo suplemento: "Es VITAL para nosotros tenerlo en el primer número del nuevo suplemento con un saludo de dos o tres líneas". ${ }^{99}$ Mills en efecto envió la siguiente nota dirigida a Fernando Benítez que se publicó en el primer número de "La cultura en México": "Me apresuro a enviarle este saludo para su nueva publicación, en SIEMPRE! De todo corazón, cuente con mi total apoyo en su nueva empresa. Estoy con usted incondicionalmente. Felicitaciones y todos mis mejores deseos para que tenga un gran éxito. Venceremos". ${ }^{100}$

96 CFP, Carta de Carl D. Brandt a Fuentes, 6 de noviembre de 1961, box 89, folder 34 .

${ }^{97}$ El 28 de diciembre, casi el mismo día que el profesor Mills regresaba a Nueva York, el Fondo publicó la $4^{a}$ y última edición de Escucha, Yanqui con un tiraje de 30000 ejemplares. Sería este el libro más vendido en 1961. Emmanuel Carballo, "La producción editorial 1961", en "La cultura en México", Siempre!, núm. 453 (9 feb. 1962).

${ }_{98}$ Coнn, “The Mexican Intelligentsia, 1950-1968”, p. 158.

99 CFP, Carta de Fuentes a Brandt, 9 de enero de 1961 (fecha en el original aunque corresponde a 1962), box 89 , folder 34 .

100 Siempre!, 452 (21 feb. 1962). 
El regreso a Estados Unidos no fue fácil y, de acuerdo a una carta de su esposa dirigida a sus suegros, Mills pasó sus últimas semanas sumido en un estado de ansiedad, temor y profunda depresión. ${ }^{101}$ Por esos mismos días Fuentes le escribía a Brandt que su nueva novela estaba a punto de publicarse y la dedicaría a "Wright, a quien debemos tanto en América Latina". ${ }^{102} \mathrm{La}$ noche del 20 de marzo, sin embargo, en forma sorpresiva C. Wright Mills murió de un segundo ataque al corazón. Su muerte estremeció a su grupo de amigos mexicanos y en particular a Carlos Fuentes, quien le escribiría a Brandt: "la muerte de Wright ha sido un golpe terrible para nosotros aquí: considerábamos que él era LA voz de los Estados Unidos. Sentimos que medio nosotros murió con él”. ${ }^{103}$

Paradojas de la vida, apenas tres semanas después del entusiasta saludo que Mills enviara a "La cultura en México", el mismo suplemento dedicó sus páginas a recordarlo con el afecto de sus amigos mexicanos. Bajo el título "Homenaje a Wright Mills" y una foto del sociólogo en la portada, se publicaron breves y sentidos textos de González Casanova, Orfila Reynal, Fuentes, García Terrés, González Pedrero y Flores Olea en los que recordaban al académico y al amigo. Todos coincidían en lo que había significado para él su encuentro con América Latina y lo que significaba su voz en la opinión pública estadounidense. Su físico de jugador de futbol americano, su trato afable, su gusto por la comida mexicana, su sencillez y su enorme agudeza intelectual eran algunas de las pinceladas que componían el homenaje. Lo completaba la publicación de un capítulo de The Marxists traducido por Fuentes expresamente para el suplemento. ${ }^{104}$

101 CWMP, Carta de Yaroslava Mills, 24 de febrero de 1962, box 4B353.

102 CFP, Carta de Fuentes a Brandt, 27 de febrero de 1962, box 89, folder 34.

103 CFP, Carta de Fuentes a Brandt, 6 de abril de 1962, box 89, folder 34.

104 “La Cultura en México”, en Siempre!, 459 (11 abr. 1962). Años después Fuentes publicó de nuevo su texto en Casa con dos puertas. Por su parte 
El 8 de abril, pocas semanas después de la muerte de Wright Mills, Fuentes debía participar en un debate en Nueva York sobre el tema “¿Cómo alcanzar el progreso en América Latina?” con Richard Goodwin, subsecretario de Estado adjunto para Asuntos Interamericanos, que sería transmitido por la NBC. Un par de días antes, sin embargo, la embajada estadounidense en la Ciudad de México le negó la visa. ${ }^{105} \mathrm{El}$ activismo del escritor lo había elevado a la categoría de radical comunista ante el ala dura del Departamento de Estado. Frente a la humillación de la embajada y en particular del embajador Thomas Mann, Fuentes decidió llevar el debate al terreno de la escritura. En una carta abierta que se publicó en las páginas de Siempre! el escritor invitaba a Goodwin a discutir sus argumentos en esa misma revista. Poco después Fuentes le explicaba a Brandt: "Simplemente no puedo aceptar la estupidez sin protestar [...] pensé en Wright mientras escribía esto. Él definitivamente no lo hubiera aceptado sin protestar". 106

Por esos mismos días se publicó The Marxists, libro póstumo con un agradecimiento de C. Wright Mills a Pablo González Casanova, Carlos Fuentes, Enrique González Pedrero "y otros amigos en la Universidad de México por sus críticas y ayuda", con quienes había discutido en el seminario de la UnAm los planteamientos del libro. ${ }^{107} \mathrm{Tal}$ y como se lo escribiera a Brandt

Política publicó el texto sin firma "Mills: Un renacentista" (1a abr. 1962). Agradezco a Eric Zolov esta referencia.

105 Siempre!, 460 (18 abr. 1962).

106 CFP, Carta de Fuentes a Brandt, 7 de abril de 1962, box 89, folder 34 .

107 Mills, The Marxists. Desde fines de abril de 1961 el propio Mills envió el borrador del libro a Orfila con la solicitud de que les hiciera llegar también una copia a Carlos Fuentes y a González Pedrero. En una breve nota le decía: “Todos, supongo, se enojarán con THE MARXIANS. ¿Pero no es ese acaso nuestro trabajo: confundir a la gente, con la esperanza de confundirla fructíferamente?”. AHFCE, CWM, Carta de Mills a Orfila, 28 de abril de 1961, exp. 73/2112. La edición en español se publicó en Ediciones Era en 1964. Véase ReYes Pérez, "Ediciones Era y Siglo XXI de Argentina”, pp. 54-55. González 
pocas semanas antes, en correspondencia de afectos Fuentes le dedicó a Mills, "verdadera voz de Norteamérica, amigo y compañero en la lucha de Latinoamérica", su nueva novela La muerte de Artemio Cruz, parte de la cual había escrito en La Habana en el transcurso de 1960. Quedaba así sellado el pacto en el que ambos se asumieron como intérpretes de la condición revolucionaria latinoamericana en Estados Unidos desde su postura compartida como vanguardia intelectual de una nueva izquierda.

\section{REFERENCIAS}

AHFCE Archivo Histórico del Fondo de Cultura Económica, Ciudad de México, México.

CWMP C Wright Mills Papers en el Briscoe Center for American History, Universidad de Texas en Austin, Estados Unidos.

CFP Carlos Fuentes Papers en la Rare Books and Special Collections, Biblioteca de la Universidad de Princeton, Estados Unidos.

ILHTS I. L. Horowitz Transaction Series. C. Wright Mills en la Eberly Family Special Collections Library, Biblioteca de la Universidad de Penn State, Estados Unidos.

Aguilar Rivera, José Antonio, La sombra de Ulises. Ensayos sobre intelectuales mexicanos y norteamericanos, México, Centro de Investigación y Docencia Económicas, Miguel Ángel Porrúa, 1998.

Altamirano, Carlos (ed.), Historia de los intelectuales en América Latina II. Los avatares de la "ciudad letrada" en el siglo xx, Buenos Aires, Katz Editores, 2010.

Beltrán Villeggas, Miguel Ángel, "El mLn: historia de un recorrido hacia la unidad (México 1957-1967)”, tesis de doctorado en estudios latinoamericanos, Universidad Nacional Autónoma de México, 2000.

Brown, David S., Richard Hofstadter. An Intellectual Biography, Chicago, The University of Chicago Press, 2006.

Casanova por su parte dedicó a Mills su libro La sociología de la explotación en 1969. 
Careaga, Gabriel, Los intelectuales y la politica en México, México, Extemporáneos, 1971.

CoHn, Deborah, "The Mexican Intelligentsia, 1950-1968: Cosmopolitanism, National Identity, and the State", en Mexican Studies/Estudios Mexicanos, 21: 1 (invierno 2005), pp. 141-182.

Donoso, José, Historia personal del “boom”, Barcelona, Anagrama, 1972.

Dubois, Jules, Fidel Castro: Rebel, Liberator, or Dictator?, Indianapolis, Ind., Bobbs-Merrill, 1959.

Estrada, Gerardo, “Ciencias Políticas en los años sesenta”, en Revista Mexicana de Ciencias Políticas y Sociales, 115-116 (ene.-jun. 1984), pp. 95-102.

Fuentes, Carlos, Casa con dos puertas, México, Joaquín Mortiz, 1970.

Fuentes, Carlos, La nueva novela hispanoamericana, México, Joaquín Mortiz, 1980.

Geary, Daniel, Radical Ambition. C. Wright Mills, the Left, and American Social Thought, California, University of California Press, 2009.

González Pedrero, Enrique, La Revolución Cubana, México, Universidad Nacional Autónoma de México, 1959.

Granados, Aimer y Sebastián Rivera Mir (coords.), Prácticas editoriales y cultura impresa entre los intelectuales latinoamericanos en el siglo xx, México, El Colegio Mexiquense, Universidad Autónoma Metropolitana-Cuajimalpa, 2018.

Hurtado, Guillermo, "Un antecedente de El Espectador: críticas a la Revolución mexicana en 1959", en Literatura Mexicana, xxI: 2 (2010), pp. 15-25.

Iber, Patrick, Neither Peace nor Freedom. The Cultural Cold War in Latin America, Cambridge, Londres, Harvard University Press, 2015.

ILlades, Carlos, La inteligencia rebelde: la izquierda en el debate público en México, 1968-1989, México, Oceano, 2012.

Keller, Renata, Mexico's Cold War. Cuba, the United States, and the Legacy of the Mexican Revolution, Nueva York, Cambridge University Press, 2015. 
Landau, Saul, “C. Wright Mills. The Last Six Months”, en Ramparts (ago. 1965), pp. 46-54.

Mac Lean y Estenós, Roberto, "El Cuarto Congreso Mundial de Sociología”, en Revista Mexicana de Sociología, 22: 1 (ene.-abr. 1960), pp. 321-329.

Mills, C. Wright, The Causes of World War Three, Nueva York, Ballantine Books, 1960.

Mills, C. Wright, “A letter to the New Left", en New Left Review, 5 (sep.oct. 1960).

Mills, C. Wright, Escucha, yanqui. La revolución en Cuba, México, Fondo de Cultura Económica, 1961.

MiLls, C. Wright, The Marxists, Nueva York, Dell Publishing, 1962.

Mills, Kathryn y Pamela Mills (eds.), C. Wright Mills. Letters and Autobiographical Writings, Berkeley University of California Press, 2001.

Montecinos, Verónica, “C. Wright Mills and Latin America”, en Guy Oakes (ed.), The Anthem Companion to C. Wright Mills, Anthem Press, 2016, pp. 119-158.

Out of Apathy. Voices of the New Left Thirty Years On, editado por by Oxford University Socialist Discussion Groups, Londres, Verso, 1989.

Pensado, Jaime M., Rebel Mexico. Student Unrest and Authoritarian Political Culture During the Long Sixties, Stanford, Stanford University Press, 2013.

Pozas, Ricardo, “Pablo González Casanova 1957-1965”, en Revista Mexicana de Ciencias Políticas y Sociales, 115-116 (ene.-jun. 1984), pp. 22-30.

Pozas, Ricardo, "La Revista Mexicana de Literatura: territorio de la nueva élite intelectual (1955-1965)", en Mexican Studies/Estudios Mexicanos, 24: 1 (invierno 2008), pp. 55-78.

Reyes Pérez, José Carlos, "Ediciones Era y Siglo XXI de Argentina: la difusión latinoamericana de la nueva izquierda", en Granados y Rivera Mir (coords.), 2018, pp. 54-55.

Reynaga Mejía, Juan Rafael, La Revolución cubana en México a través de la revista Politica: construcción imaginaria de un discurso para América Latina, 
Universidad Autónoma del Estado de México, Universidad Nacional Autónoma de México, México, 2007.

Rojas, Rafael, Fighting over Fidel. The New York Intellectuals and the Cuban Revolution, Princeton, Princeton University Press, 2016.

SERvín, Elisa, "Algunas ramas de un árbol frondoso: el cardenismo a mediados del siglo xx”, en Historias, 69 (2008), pp. 81-96.

Servín, Elisa, "Frank Tannenbaum entre América Latina y Estados Unidos en la Guerra Fría”, en A contracorriente, 13: 3 (otoño 2016), pp. 49-75.

Summers, John H., “The Epigone's Embrace: Irving Louis Horowitz on C. Wright Mills", en The Minnesota Review, 68 (primavera 2007), pp. 107-124.

Tenorio Trillo, Mauricio, “A Lost Opportunity: Carlos Fuentes, the Essay, and Mexico in English", en www.habanaelegante.com (primavera-verano 2014).

Testimonios y conversaciones. Entrevistas de Cristina Pacheco, México, Fondo de Cultura Económica, 1984.

The Politics of Truth: Selected Writings of C. Wright Mills, selección e introducción de John H. Summers, Oxford, Oxford University Press, 2008.

Treviño, A. Javier, C. Wright Mills and the Cuban Revolution: an exercise in the art of sociological imagination, Chapel Hill, University of North Carolina Press, 2017.

URÍAS HorCasitas, Beatriz, "Alianzas efímeras: izquierdas y nacionalismo revolucionario en la revista Política. Quince días de México y del Mundo (19601962)", en Historia Mexicana, LXVIII: 3 (271) (ene.-mar. 2019), pp. 1205-1252.

WeInberg, Liliana, “Cuadernos Americanos: la política editorial como política cultural”, en Altamirano (ed.), 2010, pp. 235-258.

ZoLov, Eric, "Expanding our Conceptual Horizons: The Shift from an Old to a New Left in Latin America", en A Contracorriente, 5: 2 (invierno 2008), pp. 47-73.

Zolov, Eric, The Last Good Neighbor: Mexico in the Global Sixties, Durham, Duke University Press [en prensa]. 